\title{
Assessing the Physicochemical Stability of a Compounded Neonatal Trace Element Solution
}

\author{
Forugh Sanaee ${ }^{1}$, Tania Mysak$^{2}$, Laurine Sanderson ${ }^{2}$, Theresa Donaldson ${ }^{2}$, Mohammad Reza Vakili ${ }^{1}$ and Afsaneh \\ Lavasanifar $^{1}$ \\ ${ }^{1}$ University of Alberta, Faculty of Pharmacy and Pharmaceutical Sciences, Edmonton, AB, Canada. ${ }^{2}$ Alberta Health Services, \\ Pharmacy Services, Edmonton, AB, Canada.
}

Received, May 16, 2018; Accepted, June 5, 2018; Published, July 10, 2018.

\begin{abstract}
PURPOSE: Alberta Health Services (AHS) recommends the adoption of a new neonatal multitrace element formulation containing zinc sulfate, copper sulfate, selenious acid and sodium iodide to be compounded internally in appropriate AHS pharmacies. The objective of this study was to assess the physicochemical stability of this formulation under commonly used storage conditions. METHOD: Three batches of trace element solution were compounded by University of Alberta Hospital pharmacy staff using sterile compounding procedures. Appropriate amount of zinc sulfate $(500 \mu \mathrm{g} / \mathrm{mL})$, copper sulfate $(40 \mu \mathrm{g} / \mathrm{mL})$, selenious acid $(4 \mu \mathrm{g} / \mathrm{mL})$, sodium iodide $(2 \mu \mathrm{g} / \mathrm{mL})$ and sterile water for injection were mixed. Samples from each batch were divided in individual vials and syringes for each time point and kept protected from light either at room temperature $\left(15-30^{\circ} \mathrm{C}\right)$ or fridge $\left(2-8^{\circ} \mathrm{C}\right)$. Vial samples were also kept at room temperature for $12 \mathrm{~h}$ and then transferred to fridge. Vial samples were analyzed at time $0,12 \mathrm{~h}$, and 1, 3, 7, 9, 30, 60, 90 days for their physical appearance and $\mathrm{pH}$, then centrifuged and assessed for the soluble zinc (atomic absorption), copper (atomic absorption), selenium (ICP-MS) and iodine (HPLC and ICP-MS) concentrations. Syringe samples were tested at time 0 and $12 \mathrm{~h}$ for element concentrations. RESULTS: Under all storage conditions, when stored in vials, samples' appearance, $\mathrm{pH}$ and soluble zinc, copper and selenium concentrations stayed within the USP acceptable limits up to 90 days. Iodine concentration was within the permitted limits only up to 7 days. The USP recommended HPLC method of iodine analysis seemed inadequate for this preparation and needed modifications, through frequent washing of the column with KI (2\%) solution. Samples kept in syringes at room temperature, showed lower than permitted concentration of $\mathrm{Zn}$ at $12 \mathrm{~h}$ in this study. CONCLUSION: The AHS neonatal multitrace element formulation seem to be physio-chemically stable up to 7 days in all three storage conditions when kept in vials. A decline in iodine concentration is seen after 7 days irrespective of storage conditions.
\end{abstract}

This article is open to POST-PUBLICATION REVIEW. Registered readers (see "For Readers") may comment by clicking on ABSTRACT on the issue's contents page.

\section{INTRODUCTION}

Trace elements are inorganic elements found in low concentrations in tissues and body fluids and are essential for the maintenance of human physiology. Insufficient amount of trace elements may result in serious metabolic impairments such as stunted growth, reduced physical and mental activity, increased risks of chronic diseases and prolonged recovery time following illness (1-8). Neonatal and pediatric patients are unable to orally consume sufficient amount of trace elements through food, thus must receive essential trace elements parenterally in order to avoid symptoms of trace element deficiency.
The American Society for Parenteral and Enteral Nutrition (ASPEN) guidelines state that the recommended intakes of trace elements can be achieved only through the use of individualized trace element products; however, most institutions use combination products to avoid multiple injections. (1-6, 9). Based on USP 39 (10), the trace elements injection is a sterile solution of two or more of chromium, copper, manganese, zinc, selenium, sodium iodide, and ammonium molybdate in water. In 2012, ASPEN published a position paper in which they indicated that the parenteral multi-trace element preparations that are commercially available for neonates in North America require significant modifications. In this paper, ASPEN provided recommendations for improved neonatal multi-trace 
element preparation (11). This recommendation was based on an intensive review of commercially available parenteral trace element products, which found existence of potentially toxic levels of magnesium and chromium in neonatal/pediatric multi-trace element products (12). Based on this paper, three pediatric/neonatal multi-trace elements available in the US market (Multitrace-4 Neonatal ${ }^{\circledR}$, Multitrace-4 Pediatric ${ }^{\circledR}$, Trace elements injection 4; USP-Pediatric ${ }^{\circledR}$ ) provide potentially toxic amounts of manganese and chromium in comparison to the ASPEN recommendation (13).

The literature indicates that an ideal neonatal trace element solution should contain zinc, selenium, copper and iodine (14). Chromium and manganese are not necessary, as both exist as contaminants in multiple parenteral nutrition ingredients including amino acids and electrolytes; often in quantities that meet or exceed the needs even in long-term parenteral nutrition. Neonatal/pediatric trace element combination products currently available in North America contain excessive copper, manganese, and chromium and insufficient quantities of selenium. Based on concerns about the potential toxicity of the commercially available products and the need for multi-trace element products, the Alberta Health Services (AHS) Provincial Parenteral Nutrition Steering Committee recommended the adoption and implementation of a new neonatal multi-trace element formulation that would be compounded internally at appropriate AHS compounding facilities. This formulation is prepared by mixing zinc sulfate, copper sulfate, selenious acid and sodium iodide stock solutions at pre-calculated volumes and then using sufficient amount of water for injection to achieve the desired volume.

Copper is cofactor for several oxidative metalloenzymes such as lysyl oxidase and supports collagen synthesis, iron transport, antioxidant activity, and neurotransmitter and melanin production. Its function is important for transferrin, leukocyte production and bone formation $(15,16)$. Selenium, which has critical role in thyroid metabolism, prevents tissue from oxidative damage $(15,16)$. Iodine is an important factor in cellular oxidation and an essential element for the formation of thyroid hormones and its deficiency results in cognitive and mental impairment. Zinc is a cofactor for more than 300 metalloenzymes, and its role is very important and critical for normal growth and immune functions and it maintains the integrity of skin and gastrointestinal tract mucosa $(15,16)$. Mixing of these elements in a compounded formulation provides the required combination that is not commercially available for administration to neonatal/pediatric patients. As a combination product, the volumes are large enough for the dose to be added to the parentral nutrition (PN) bags via an automated compounding device (ACD) thereby decreasing the number of manual additions, which is an important consideration for safety and sterility.

The objective of this study was to assess the physicochemical stability of AHS compounded Neonatal/Pediatric Trace Element Solution based on National Association of Pharmacy Regulatory Authorities (NAPRA) and USP criteria at room (15$\left.30^{\circ} \mathrm{C}\right)$ and/or fridge $\left(2-8^{\circ} \mathrm{C}\right)$ temperatures. Moreover, potentially to provide recommendations on the expiration dating of this compounded trace element formulation with respect to its chemical and physical properties.

\section{EXPERIMENTAL SECTION MATERIALS}

Zinc sulfate ( $1 \mathrm{mg} / \mathrm{mL}$ Injection USP), cupric sulfate $(0.4 \mathrm{mg} / \mathrm{mL}$ Injection USP), selenious acid (40 $\mu \mathrm{g} / \mathrm{mL}$ Injection USP), sodium iodide $(100 \mu \mathrm{g} / \mathrm{mL}$ Injection USP) were supplied by Sandoz, Sandoz Canada Incorporated. Standard selenium (ICP international, California, USA), dibasic sodium phosphate (Fisher Chemical, Canada), cetyltrimethylammonium chloride (Aldrich, Canada), acetonitrile (Sigma-Aldrich, Canada), water (HPLC grade, Fisher Chemical, Canada), potassium iodide (Sigma-Aldrich, Canada), zinc and copper standards (Fisher Scientific, Canada) were also used in this study. Vials $(50 \mathrm{~mL})$ were purchased from Healthmark. Vials ( $5 \mathrm{~mL})$ were purchased from McKesson Canada. The syringes were Becton Dickinson syringes and purchased from Medical Mart Supplies Ltd. The amber UV ziplock bags that were used for light protection were purchased from PharmaSystems.

\section{METHODS}

\section{Compounding of neonatal/pediatric trace elements solution}

Compounding of neonatal/pediatric trace elements solution was carried out by AHS pharmacy staff at the University of Alberta Hospital using sterile compounding procedures. Appropriate personal 
protective equipment (PPE), aseptic technique and strict hygiene were followed according to AHS Pharmacy Services Sterile Compounding Orientation and Training Manual at all times to maintain asepsis and reduce the risk of contamination. Three separate batches of neonatal/pediatric trace element solution were compounded (Batch A, Batch B, and Batch C). All ingredients and supplies for each batch were placed into the primary engineering control (PEC) hood. Appropriate amount of zinc (as zinc sulfate; 500 $\mu \mathrm{g} / \mathrm{mL}$ ), copper (as copper sulfate; $40 \mu \mathrm{g} / \mathrm{mL}$ ), selenium (as selenious acid; $4 \mu \mathrm{g} / \mathrm{mL}$ ), iodine (as sodium iodide; $2 \mu \mathrm{g} / \mathrm{mL}$ ) were withdrawn one at a time, into the appropriately sized syringes, the needles recapped; and the filled syringes placed in position beside the corresponding vials. The correct volume of sterile water was withdrawn and the sterile water for injection and the trace elements were transferred into an empty $250 \mathrm{~mL}$ viaflex IV bag and mixed well, then visually inspected for particulates and bag integrity.

\section{Storage conditions}

Samples from each batch were divided in individual vials and syringes for each time point and placed in amber ziplock bags. The samples were kept in three different storage conditions as follows:

1. Vials and syringes were stored at room temperature $\left(15-30^{\circ} \mathrm{C}\right)$ and protected from light.

2. Vials and syringes were stored in fridge (2$8^{\circ} \mathrm{C}$ ) and protected from light.

3. Vials were stored only at room temperature $\left(15-30^{\circ} \mathrm{C}\right)$ for $12 \mathrm{~h}$ and then transferred to fridge $\left(2-8^{\circ} \mathrm{C}\right)$ while protected from light.

\section{Time and sampling intervals}

Samples from each batch and storage condition were analyzed at time 0 and $12 \mathrm{~h}$ for their trace element levels. Samples kept in vials in different storage temperatures were also analyzed at 1, 3, 7, 9, 30, 60 and 90 days after compounding for their physical appearance, $\mathrm{pH}$ and the concentration of the trace elements using the methods described below.

\section{Tests of physical stability}

Physical appearance of the samples was evaluated in each time point by visual inspection of the samples for signs of particulate matter and color change. The appearance of particulate matter was also investigated by visual inspection of formation of any precipitate following 10 minutes centrifugation (Fixed Speed controller set to 3400 RPM, for 5 minute). The $\mathrm{pH}$ of all samples was determined (Accumet $^{\circledR}$, Fisher Scientific) during the storage in each time point.

\section{Analytical methods for chemical stability testing \\ Zinc assay}

Samples were analyzed for zinc using an atomic absorption spectrophotometer (AGILENT 220 FS AAS) based on USP 39 (10). The required specific hallow cathode lamp was selected with a sensitive line of $213.9 \mathrm{~nm}$, operating at $1 \mathrm{~mA}$ with a maximum of $4 \mathrm{~mA}$. A vapor generator (Varian, USA) was used to aid the direction of the acetylene-air flame inside the instrument. The instrument was adjusted to zero with double distilled water. A calibration cure using a series of standards of known zinc concentrations $(0.1-3 \mu \mathrm{g} / \mathrm{mL})$ used to quantify the unknown zinc concentration in each sample.

\section{Selenium assay}

Based on USP 39, the selenium method of assay is atomic absorption (10). There was no facility for measuring selenium by atomic absorption in University of Alberta. As a result, we used an Inductively Coupled Plasma (ICP) apparatus (Perkin Elmer 's Elan 6000) to measure selenium levels in the samples (ranging from 10-100 $\mu \mathrm{g} / \mathrm{mL}$ ). Samples for ICP-MS quantification were prepared by adding $0.1 \mathrm{~mL} \mathrm{HNO}_{3}, 0.1 \mathrm{~mL}$ of internal standards (Bismuth, Indium, Scandium) and $8.8 \mathrm{~mL}$ double distilled water. The instrument conditions included: ICP RF power $1300 \mathrm{~W}$; dual detector mode; and measurement units were cps (counts per second). The flow rate was set at $1 \mathrm{~mL} / \mathrm{min}$. We used 35 sweeps per reading. The results were the average of three replicates. Standard curves were linear over the concentration range of 5 to $1000 \mathrm{ng} / \mathrm{ml}(R 2 \geq 0.99$, coefficient of variation $\leq 10 \%$ ).

\section{Copper assay}

Samples were analyzed for copper using an atomic absorption spectrophotometer (10). The instrument used was AGILENT 220 FS AAS. The required specific copper hallow cathode lamp was selected with a sensitive line of $324.7 \mathrm{~nm}$, operating at $1 \mathrm{~mA}$ with a maximum of $4 \mathrm{~mA}$. A vapor generator (Varian, USA) was used to aid the direction of the 
acetylene-air flame inside the instrument. The instrument was adjusted to zero using sodium chloride solution $(10 \%)$ and water (1 in 10$)$. A calibration curve using a series of standards of known copper concentrations $(0.3-3 \mu \mathrm{g} / \mathrm{mL})$ were used to quantify copper level in the samples.

\section{Iodine assay}

A USP-based HPLC method was used to measure iodine levels (10). The HPLC apparatus consisted of a Mandel 234 auto-injector and a UV detector (Shimadzu, SPD-10A). Chromatographic separation was performed using a Discovery ${ }^{\circledR} \mathrm{C} 18$ HPLC column of $5 \mu \mathrm{m}$ particle size, $\mathrm{L} \times$ I.D. 25 $\mathrm{cm} \times 4.6 \mathrm{~mm}$ (Sigma, Canada). The mobile phase was eluted at a flow rate of $0.8 \mathrm{~mL} / \mathrm{min}$ and effluent was monitored at $226 \mathrm{~nm}$. Standard curves were linear over the concentration range of 1 to $10 \mu \mathrm{g} / \mathrm{mL}\left(R^{2} \geq 0.99\right.$, coefficient of variation $\leq$ $10 \%$ ). A mixture of $0.05 \mathrm{M}$ dibasic sodium phosphate, $0.0025 \mathrm{M}$ cetyltrimethylammonium chloride and acetonitrile was used at 45:25:25 as mobile phase. The $\mathrm{pH}$ of mobile phase was adjusted to $6.8 \pm 0.1$ using phosphoric acid. At the end of running each set of standards and samples (after each day of measurement), the column was washed with $2 \%$ solution of KI for about $2 \mathrm{~h}$ to prevent column blockage which was observed during the measurements upon repeated injections of the mixture elements to the reverse phase HPLC column.

For a few time points, we also used ICP-MS to assess the total level of iodine. Total iodine concentration analysis was performed using flow injection (FI) coupled with Agilent 7500 Inductively Coupled Plasma Mass Spectrometry (FI-ICPMS). Nitric acid $\left(1 \% \mathrm{HNO}_{3}\right)$ was used as the mobile phase, the flow rate was set at $1.2 \mathrm{~mL} / \mathrm{min}$ and an injector loop of $20 \mu \mathrm{L}$ was used. The flow rate of plasma gas was $15 \mathrm{~L} / \mathrm{min}$, and the nebulizer gas was $0.95-0.98$ $\mathrm{mL} / \mathrm{min}$. Peaks at $\mathrm{M} / \mathrm{Z} 127$ was monitored for iodine. Standard curve was linear over the concentration range of $1.25-20 \mathrm{ng} / \mathrm{mL}$. Appropriate dilutions of the test samples were prepared in $1 \%$ nitric acid. Agilent chromatographic data analysis software was used for data analysis.

\section{Data recording, reporting and final evaluation}

The raw data were used to plot the percentage of remaining element in the compounded solution versus time. Products having $90-110 \%$ of labeled amount for each element in the solution under study and no sign for the presence of particulate matter or $\mathrm{pH}$ changes were considered physico-chemically stable. Data are presented as the mean \pm standard deviation. Two-way ANOVA followed by Bonferroni as the post hoc were used to assess the statistical significance. $P$-values less than 0.05 were considered significant for all statistical tests.

\section{RESULTS}

\section{Appearance}

Under all three storage conditions, samples' appearance stayed clear, colorless and free of any precipitation during 90 days of stability study.

\section{pH}

The $\mathrm{pH}$ of the solutions during the storage period is shown in Figure 1. pH of samples in all storage conditions stayed within USP (10) acceptable criteria $(\mathrm{pH}, 1.5-3.5)$.

\section{Zinc, copper, selenium and iodine analysis and stability}

For the measurement of soluble levels of zinc, copper and selenium in the samples, we centrifuged the samples at each time point and took an aliquot from the top to measure the level of different elements. We used either USP recommended method of atomic absorption (in case on $\mathrm{Zn}$ and $\mathrm{Cu}$ ) or ICPMS, which measured the Se levels with acceptable sensitivity. Our data showed that the concentration of $\mathrm{Se}, \mathrm{Cu}$ and $\mathrm{Zn}$ (Fig 2A-C) to stay within the permitted limit in all storage conditions up to 90 days following compounding, except for $\mathrm{Zn}$ when the multi-trace element solution was stored in vials (Fig 2A) or syringes (Fig 3A) at room temperature for 12 $\mathrm{h}$. Under the latter condition, $\mathrm{Zn}$ concentration in all 3 batches appeared to be below the permitted limit and around $85 \%$ of the labeled quantity. For samples in vials kept at room temperature, the $\mathrm{Zn}$ concentration was found to be acceptable in later time points (1-90 days) (Fig 2A). Therefore, the 12$\mathrm{h}$ data for this storage condition was considered to be the result of an error either in the preparation or dilutions for the measurement of samples. For samples kept in syringes and at room temperature (Fig 3A), since there is no measurement beyond 12 $\mathrm{h}$, the same cannot be concluded and they are warranted in this case. Further studies are underway to investigate the appropriateness of storage in syringes for this multi-trace compounded solution, 
especially with respect to $\mathrm{Zn}$ concentration when stored at room temperature.

At any given time point, no significant difference between concentration of these three elements was shown under different storage condition during 90 days of storage in most cases $(P$ $>0.05$, two-way ANOVA), except for one point at 3 -day $\mathrm{Zn}$ concentration at room versus 12 -h room and then fridge concentration (Figure 2A). This shows that the storage condition did not affect the stability of elements in solution. We also compared the level of each element at any given storage condition over time. Our statistical analysis showed no significant difference in this case either. For samples kept in syringes (Figure 3A), there was significant difference in $\mathrm{Zn}$ concentration between "fridge" and "room" temperature only at $12 \mathrm{~h}(P<$ 0.05, two-way ANOVA).

Iodine concentration was within the permitted limits only up to 7 days in all three storage conditions. The concentration of iodine appeared below the permitted level (less than 90 percent of labeled amount) after 7 days of stability study irrespective of the storage conditions (Fig 2D). Our statistical analysis showed no significant difference between samples stored under different conditions for iodine concentration $(P>0.05$, two-way ANOVA up to 7 days). For iodine analysis, a USP recommended HPLC method specific to compounded trace elements was used (10). This method, on its own, was found not to be appropriate for the trace element mixture solution under study, leading to the blockage of HPLC column. Column wash during samples with saturated potassium iodide was needed to remove the blockade and make the column usable and the analysis accurate during the subsequent HPLC runs of the samples. To validate the HPLC results, ICP-MS was used to measure total iodine concentration of samples in Fig 2D at selected time points. The ICP-MS measurements confirmed the stability of iodine in solution up to 7 days (Fig 4).

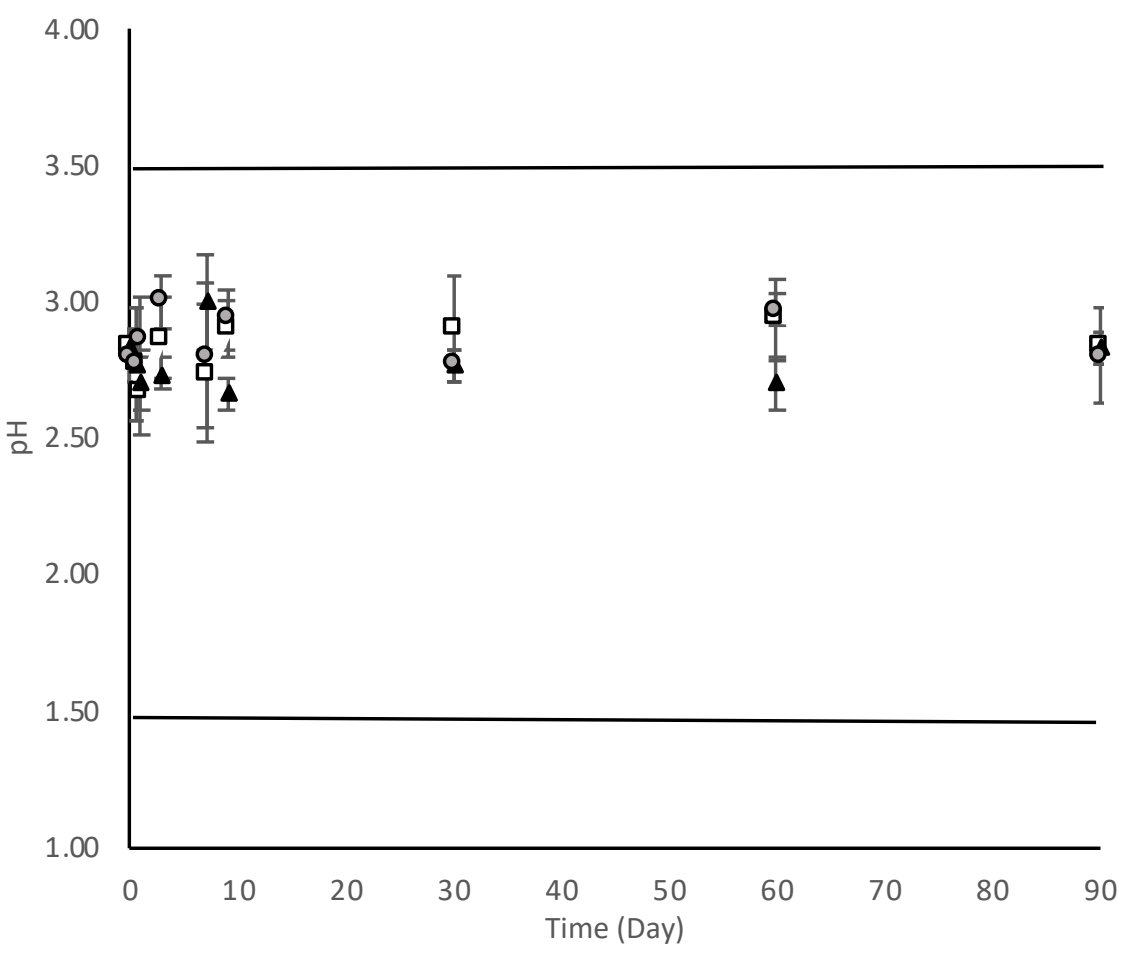

a $\mathrm{pH}$ at room temprature

$\mathrm{pH} 12 \mathrm{~h}$ in room then transferred to fridge

- $\mathrm{pH}$ in the fridge

Figure 1. Changes in the $\mathrm{pH}$ of compounded neonatal solution during 90 days of storage in three different conditions. 
A)

$\mathrm{Q} \mathrm{Zn}$ at room

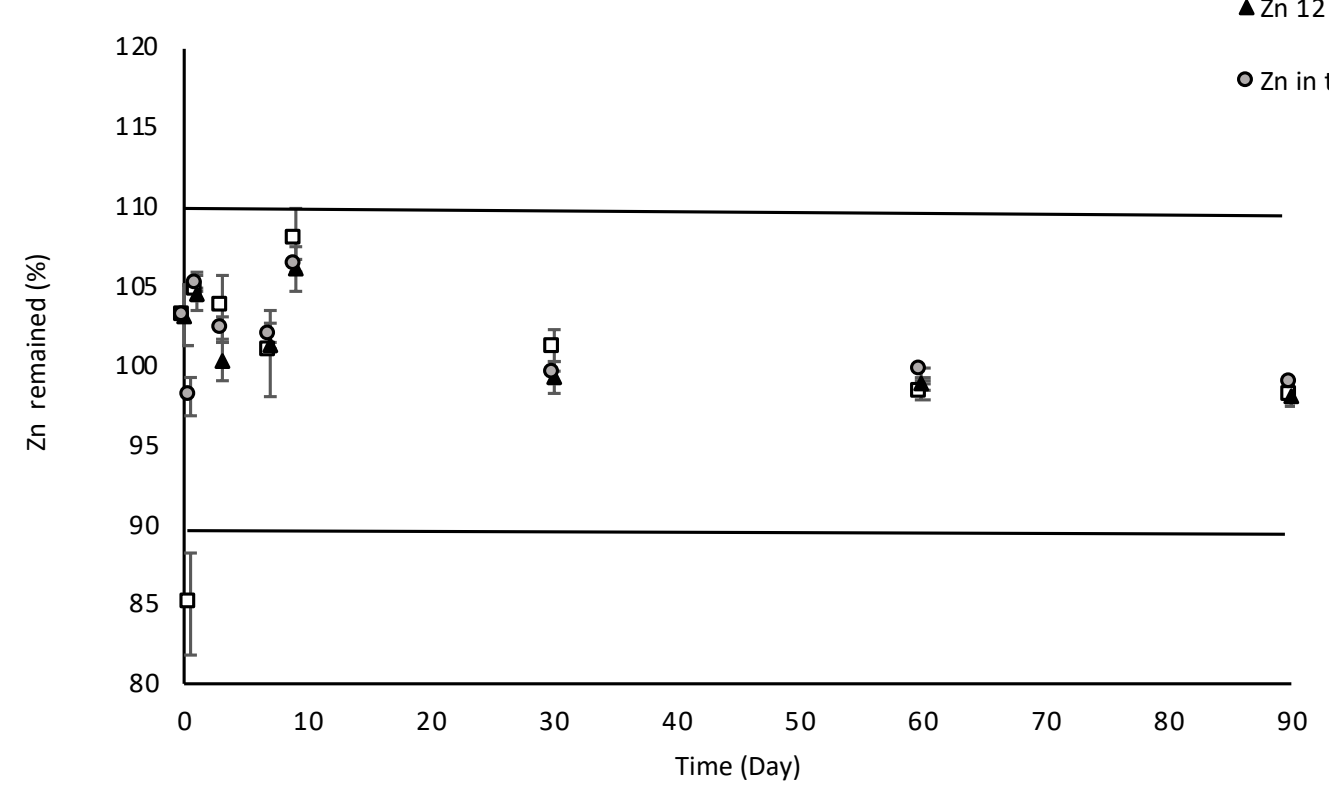

B)




C)

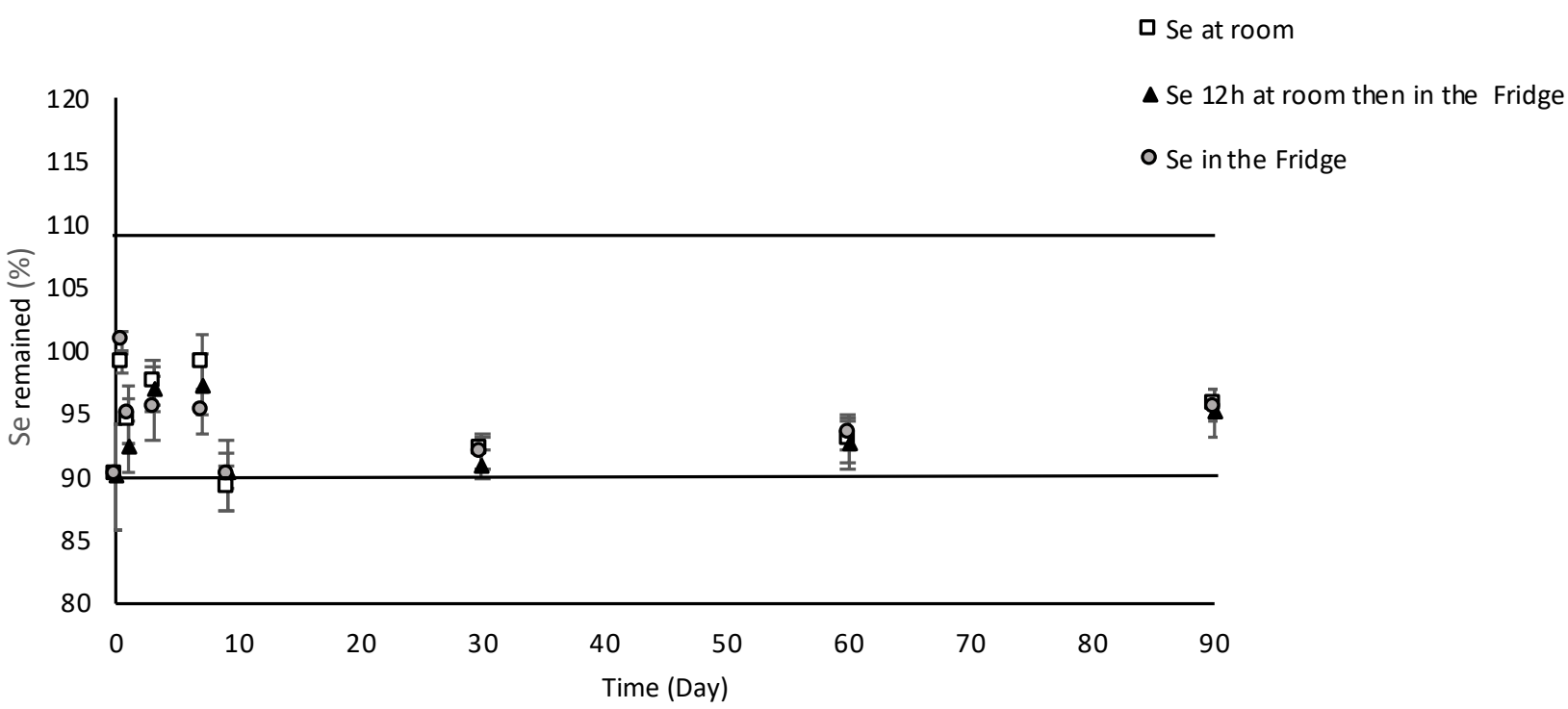

D)

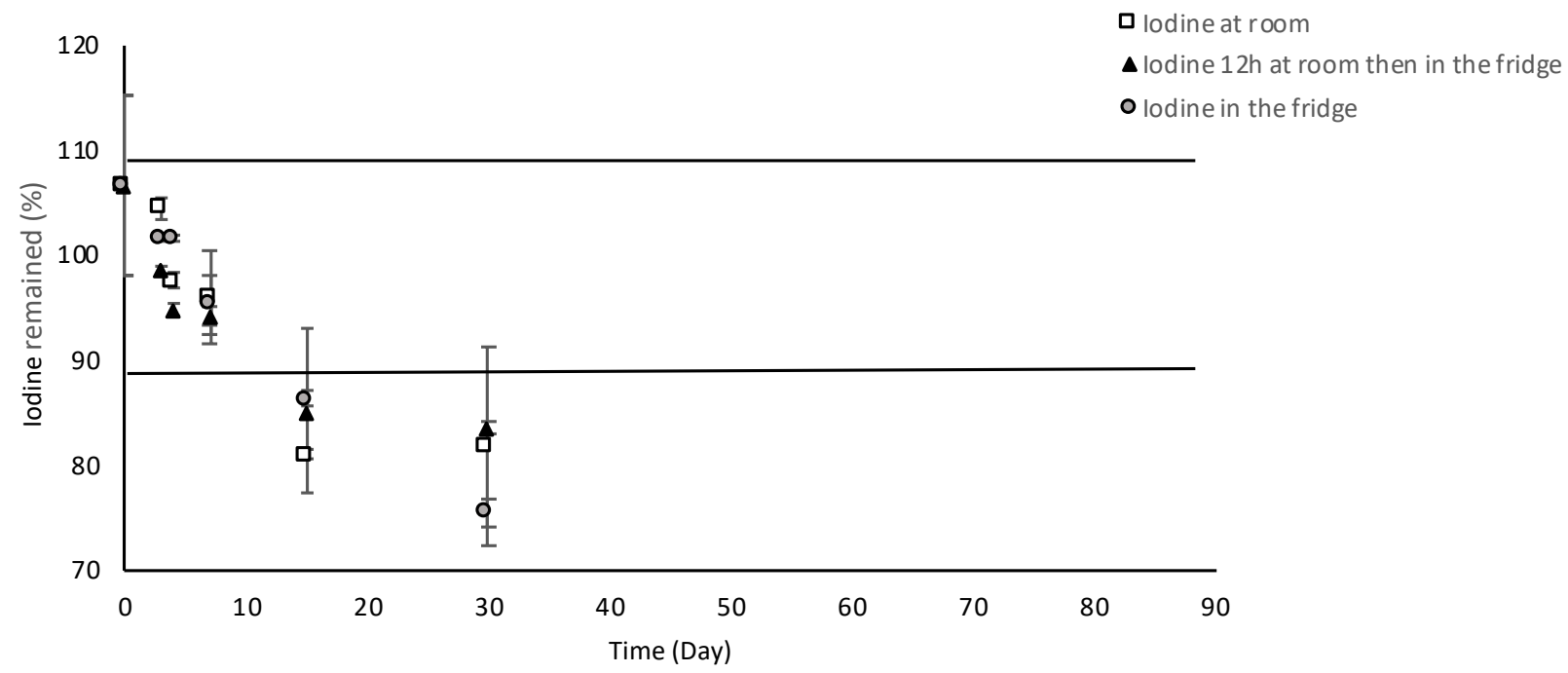

Figure 2. Percentage of remaining A) zinc $(\mathrm{Zn}), \mathrm{B})$ copper $(\mathrm{Cu}), \mathrm{C})$ selenium $(\mathrm{Se})$; and $\mathrm{D})$ iodine during storage of compounded neonatal trace element solution in vials under different storage conditions.

\section{DISCUSSION}

A trace element mixture is preferred over use of single trace elements because it reduces the need for several injections into the PN bag. Parenteral nutrition compounding is a complex process and is categorized as medium risk preparation by the NAPRA. The fewer the number of manual additions into the PN, the safer is the process. Where an ACD is used to compound $\mathrm{PN}$, the volume of a trace element mixture dose is large enough to be added to the PN via this device, whereas the volumes of the individual trace elements are too small. Where an ACD is not available, manual additions are required and utilizing a mixture decreases the risks of error and contamination associated with drawing up, checking and injecting each ingredient separately for each PN bag. 
A)

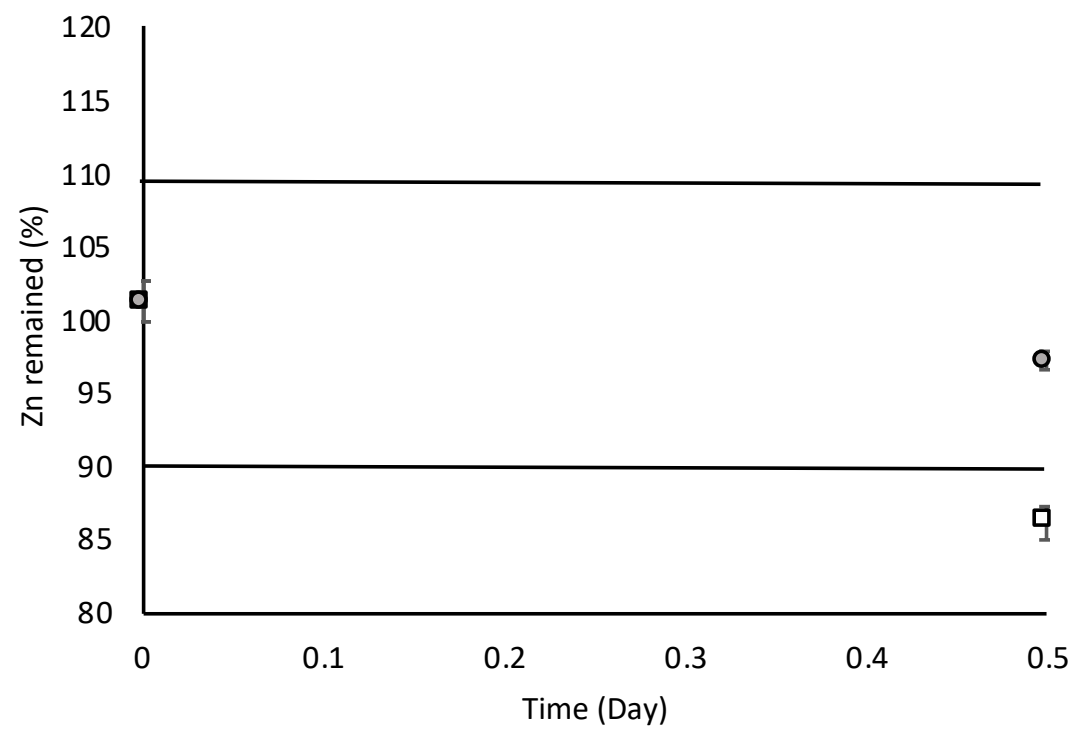

$\square \mathrm{Zn}$ at room

$0 \mathrm{Zn}$ in the Fridge

B)

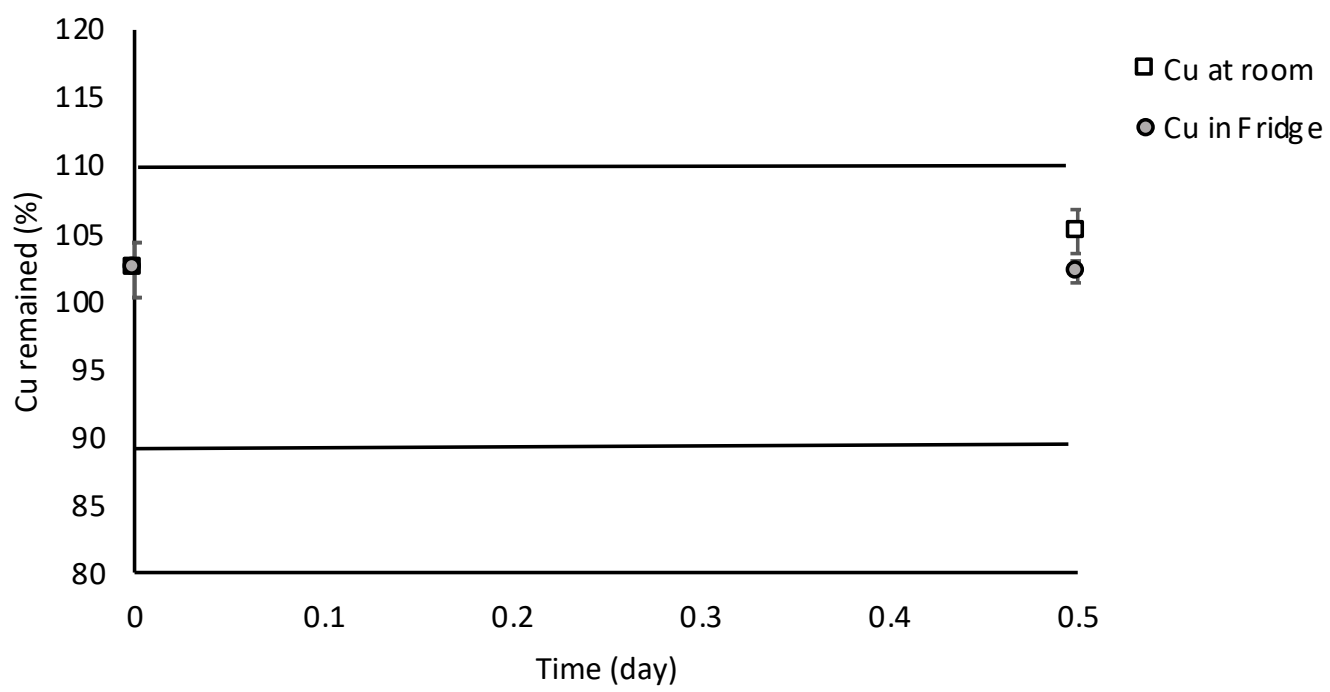

C)

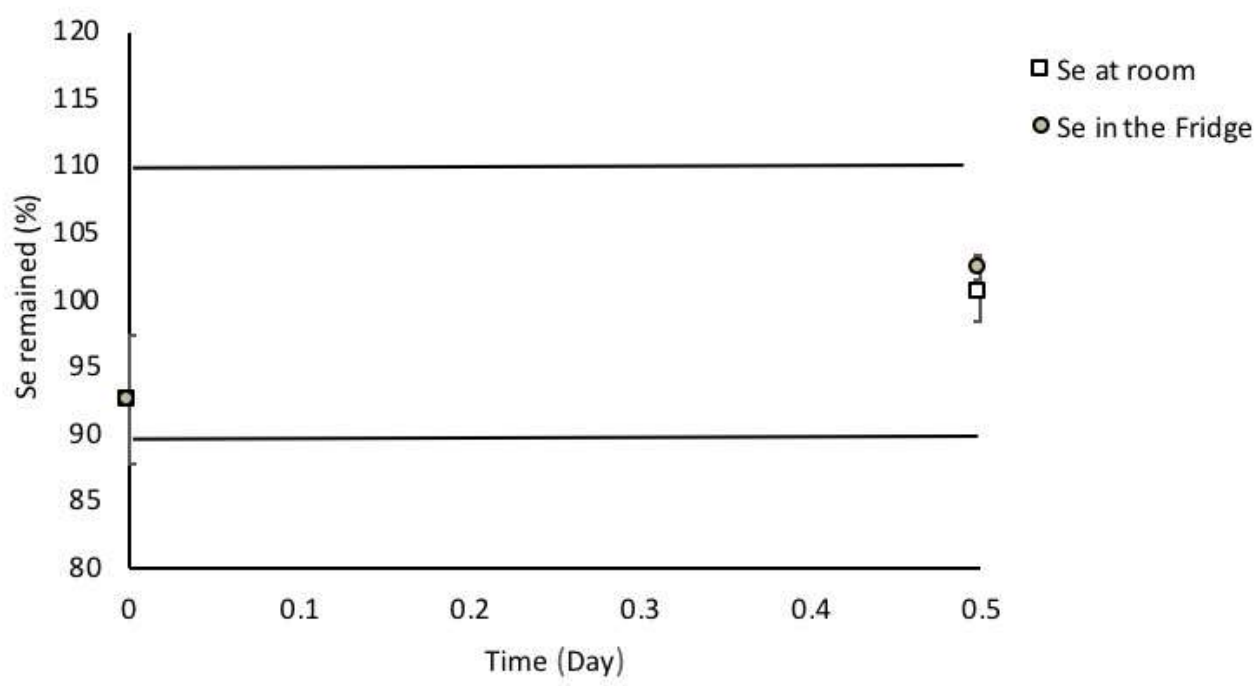


D)

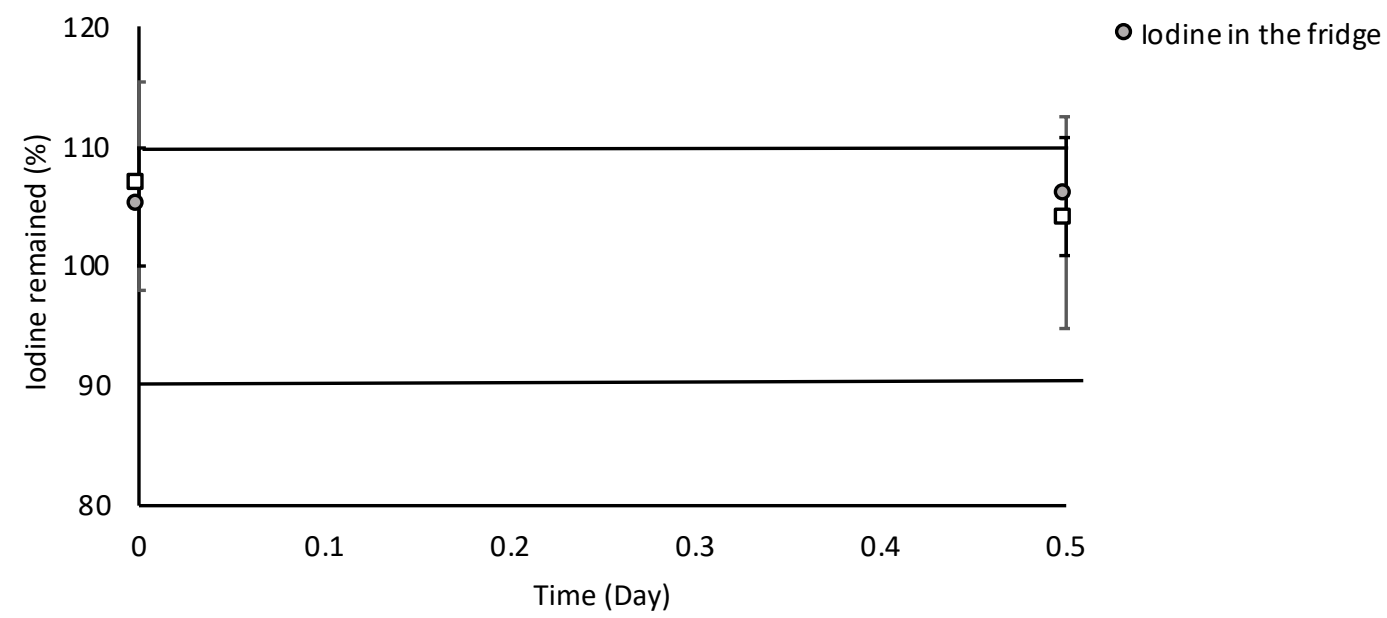

Figure 3. Percentage of remaining A) zinc ( $\mathrm{Zn}), \mathrm{B})$ copper $(\mathrm{Cu}), \mathrm{C})$ selenium $(\mathrm{Se})$; and $\mathrm{D})$ iodine in syringes under different storage conditions.

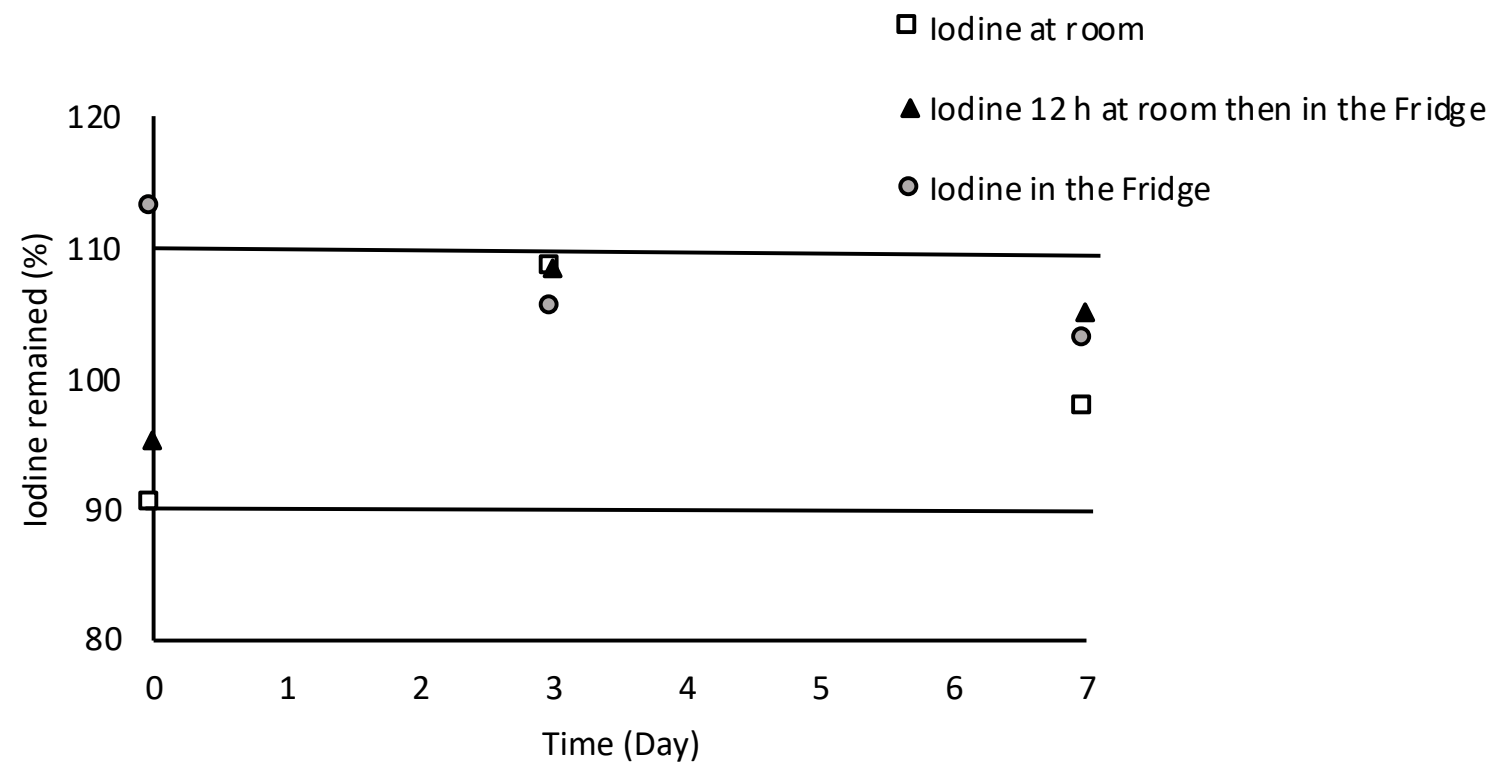

Figure 4-Percentage of remaining Iodine during storage of compounded neonatal solution as measured by ICP-MS in vials under different storage conditions.

The objective of this study was to assess the physicochemical stability of an aqueous compounded trace element mixture consisting of zinc sulfate, copper sulfate, selenious acid and sodium iodide prepared for injection and to be used in parenteral nutrition for neonatal and pediatric patients. The trace element mixture is intended to prevent serious metabolic impairments such as stunted growth, reduced physical and mental activity, increased risks of chronic diseases and prolonged recovery time following illness in neonatal and pediatric patients who are unable to orally consume sufficient amount of trace elements in order to avoid symptoms of trace element deficiency. The selected storage conditions were based on NAPRA and the preparation risk level. Storage containers were selected from those approved for sterile compounding at the University of Alberta Hospital pharmacy, where compounding of neonatal/pediatric trace elements solution is carried out. 
Table 1- A) Remaining concentration of zinc, copper and selenium and B) Iodine in the compounded neonatal trace element solution at room temperature.

A)

\begin{tabular}{|c|c|c|c|c|c|c|c|c|c|c|c|}
\hline Time & 0 & & $12 \mathrm{~h}$ & & 1 day & 3 day & 7 day & 9 day & 30 day & 60 day & 90 day \\
\hline Storage & Syringe & Vial & Syringe & Vial & & & & & & & \\
\hline \multicolumn{12}{|l|}{ Container } \\
\hline \multirow{2}{*}{$\begin{array}{l}\text { Concentration } \\
\text { of Zinc } \\
(\mu \mathrm{g} / \mathrm{mL})\end{array}$} & 506.3 & 515.8 & 430.80 & 425.13 & 523.57 & 517.83 & 504.20 & 539.37 & 505.03 & 491.73 & 490.63 \\
\hline & \pm 6.99 & \pm 9.05 & \pm 6.14 & \pm 16.19 & \pm 6.11 & \pm 10.19 & \pm 13.59 & \pm 9.86 & \pm 6.70 & \pm 2.25 & \pm 3.29 \\
\hline \multirow{2}{*}{$\begin{array}{l}\text { Concentration } \\
\text { of Copper } \\
(\mu \mathrm{g} / \mathrm{mL})\end{array}$} & 40.93 & 41.8 & 42.03 & 41.17 & 42.50 & 42.83 & 42.90 & 42.17 & 42.17 & 41.33 & 41.23 \\
\hline & \pm 0.81 & \pm 0.30 & \pm 0.65 & \pm 0.45 & \pm 0.43 & \pm 0.15 & \pm 0.30 & \pm 0.25 & \pm 0.12 & \pm 0.12 & \pm 0.40 \\
\hline \multirow{2}{*}{$\begin{array}{l}\text { Concentration } \\
\text { of Selenium } \\
(\mu \mathrm{g} / \mathrm{mL})\end{array}$} & 3.69 & 3.6 & 4.01 & 3.96 & $3.78 \pm 0.07$ & $3.90 \pm 0.07$ & $3.96 \pm 0.09$ & $3.56 \pm 0.07$ & $3.68 \pm 0.06$ & $3.71 \pm 0.06$ & $3.83 \pm 0.05$ \\
\hline & \pm 0.19 & \pm 0.17 & \pm 0.08 & \pm 0.04 & & & & & & & \\
\hline
\end{tabular}

B)

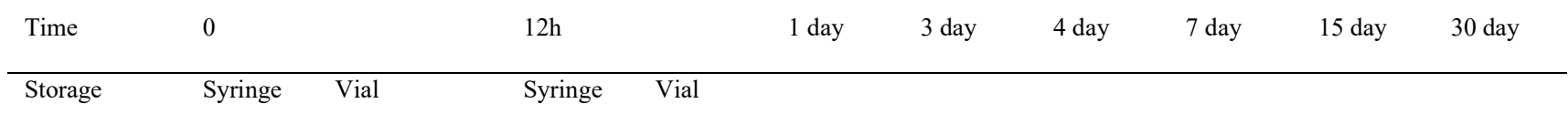

Container

\begin{tabular}{|c|c|c|c|c|c|c|c|c|c|c|}
\hline $\begin{array}{l}\text { Concentration } \\
\text { of Iodine } \\
\text { (ug/mL, } \\
\text { based on } \\
\text { HPLC) }\end{array}$ & $2.1 \pm 0.04$ & $2.1 \pm 0.17$ & $2.1 \pm 0.24$ & $2.2 \pm 0.18$ & $2.1 \pm 0.21$ & $2.0 \pm 0.07$ & $1.9 \pm 0.14$ & $1.8 \pm 0.14$ & $1.5 \pm 0.07$ & $1.6 \pm 0.26$ \\
\hline $\begin{array}{l}\text { Concentration } \\
\text { of Iodine } \\
\text { (ug/mL, } \\
\text { based on } \mathrm{CP} \text { - } \\
\text { MS) }\end{array}$ & - & $1.9920 \pm 0.2410$ & & - & - & 2.1696 & - & 1.9544 & - & - \\
\hline
\end{tabular}


Table 2- A) Remaining concentration of Zinc, Copper and Selenium; and B) Iodine in the compounded neonatal trace element solution stored in the fridge $(2-8 \mathrm{C})$.

A)

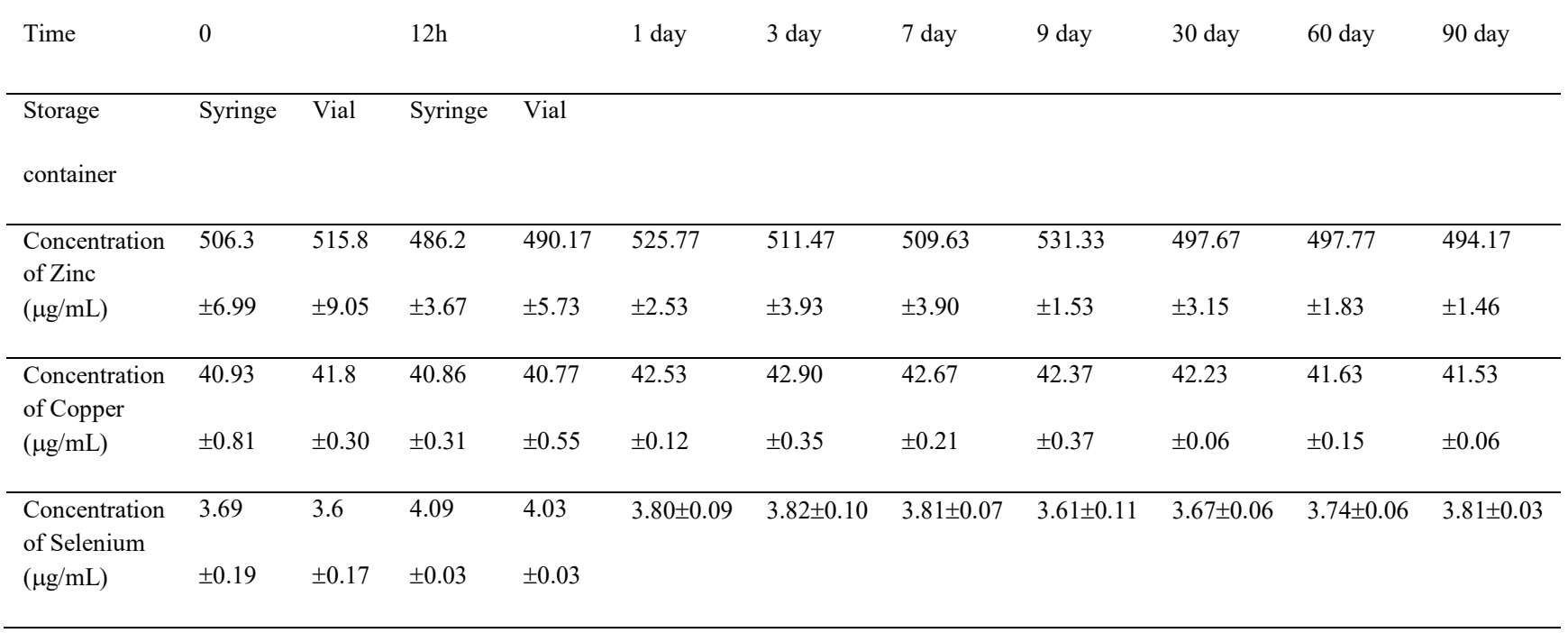

B)

\begin{tabular}{|c|c|c|c|c|c|c|c|c|c|c|}
\hline Time & 0 & & $12 \mathrm{~h}$ & & 1 day & 3 day & 4 day & 7 day & 15 day & 30 day \\
\hline Storage & Syringe & Vial & Syringe & Vial & & & & & & \\
\hline
\end{tabular}

\begin{tabular}{|c|c|c|c|c|c|c|c|c|c|c|}
\hline $\begin{array}{l}\text { Concentration } \\
\text { of Iodine } \\
\text { (ug/mL, } \\
\text { based on } \\
\text { HPLC) }\end{array}$ & $2.1 \pm 0.04$ & $2.1 \pm 0.17$ & $2.2 \pm 0.06$ & $2.0 \pm 0.05$ & $2.0 \pm 0.15$ & $2.0 \pm 0.06$ & $1.8 \pm 0.04$ & $1.9 \pm 0.10$ & $1.5 \pm 0.07$ & $1.2 \pm 0.02$ \\
\hline $\begin{array}{l}\text { Concentration } \\
\text { of Iodine } \\
\text { (ug/mL, } \\
\text { based on CP- } \\
\text { MS) }\end{array}$ & - & $1.9920 \pm 0.2410$ & & - & - & 2.1074 & - & 2.0599 & - & - \\
\hline
\end{tabular}

Under the commonly practiced storage conditions, i.e., either at room temperature $\left(15-30{ }^{0} \mathrm{C}\right)$ and protected from light, or at fridge $\left(2-8{ }^{0} \mathrm{C}\right)$ and protected from light, or room temperature (15-30 $\left.{ }^{0} \mathrm{C}\right)$ up to $12 \mathrm{~h}$ and then fridge $\left(2-8{ }^{0} \mathrm{C}\right)$ while protected from light, the appearance of samples remained similar to the time of their compounding. In other words, the samples remained colorless and free of any particulate matter. The results showed that the $\mathrm{pH}$ stayed in acceptable range of USP, i.e., 1.5 to 3.5 , as well. 
Table 3- A) Remaining concentration of Zinc, Copper and Selenium and B) Iodine in the compounded neonatal trace element solution temperature stored $12 \mathrm{~h}$ at room temperature $(15-30 \mathrm{C})$ then transferred to fridge $(2-8 \mathrm{C})$.

A)

\begin{tabular}{lllllllll} 
Time & 0 & $12 \mathrm{~h}$ & 1 day & 3 day & 7 day & 9 day & 30 day & 60 day \\
\hline Storage & Vial & & & & & & & \\
container & & & & & & & & \\
\end{tabular}

\begin{tabular}{|c|c|c|c|c|c|c|c|c|c|}
\hline $\begin{array}{l}\text { Concentration } \\
\text { of Copper } \\
(\mu \mathrm{g} / \mathrm{mL})\end{array}$ & $41.8 \pm 0.30$ & $41.17 \pm 0.45$ & $42.80 \pm 0.26$ & $43.07 \pm 0.12$ & $42.43 \pm 0.21$ & $42.60 \pm 0.26$ & $42.27 \pm 0.12$ & $41.47 \pm 0.12$ & $41.27 \pm 0.25$ \\
\hline $\begin{array}{l}\text { Concentration } \\
\text { of Selenium } \\
(\mu \mathrm{g} / \mathrm{mL})\end{array}$ & $3.6 \pm 0.17$ & $3.96 \pm 0.04$ & $3.70 \pm 0.08$ & $3.88 \pm 0.07$ & $3.89 \pm 0.09$ & $3.62 \pm 0.06$ & $3.64 \pm 0.04$ & $3.71 \pm 0.09$ & $3.80 \pm 0.07$ \\
\hline
\end{tabular}

B)

\begin{tabular}{|c|c|c|c|c|c|c|c|}
\hline Time & 0 & 1 day & 3 day & 4 day & 7 day & 15 day & 30 day \\
\hline
\end{tabular}

\begin{tabular}{|c|c|c|c|c|c|c|c|c|}
\hline $\begin{array}{l}\text { Concentration of } \\
\text { Iodine (ug/mL, based } \\
\text { on HPLC) }\end{array}$ & $2.1 \pm 0.04$ & $2.1 \pm 0.17$ & $2.0 \pm 0.01$ & $2.0 \pm 0.05$ & $1.8 \pm 0.05$ & $1.8 \pm 0.13$ & $1.5 \pm 0.07$ & $1.4 \pm 0.08$ \\
\hline $\begin{array}{l}\text { Concentration of } \\
\text { Iodine ( } \mathrm{ug} / \mathrm{mL} \text {, based } \\
\text { on CP-MS) }\end{array}$ & - & $1.9920 \pm 0.2410$ & - & 2.1705 & - & 2.1043 & - & - \\
\hline
\end{tabular}

For the evaluation of chemical stability, the chosen analytical methods of measurement for zinc, copper and selenium were based on either atomic absorption or ICP-MS that measures the total amount of these elements in the sample. The applied methods were recommended by USP for the measurement of zinc, and copper in trace elements in water for injection. Under all three storage conditions concentration of zinc, copper and selenium in the aqueous solution stayed within USP acceptable criteria (not less than 90 percent and not more than 110 percent of the labeled amounts). The storage temperature did not affect the chemical integrity of these elements in the mixture of compounded neonatal/pediatric trace elements over time when kept in vials. The same still cannot be concluded for $\mathrm{Zn}$ when stored in syringes and at room temperature, even up to $12 \mathrm{~h}$. This point needs further investigations. 
For the iodine measurement, we used the HPLC method recommended by USP, but faced the problem of column blockage during the measurements upon repeated injections of the mixture elements to the $\mathrm{C} 18$ reverse phase column. Since the problem was not observed for sodium or potassium iodide standards, we hypothesized the involvement of other elements in the compounded trace element mixture (apart from $\mathrm{NaI}$ ) to have contributed to the column blockade. Further studies implied that the blockade of the column might have been resulted from the formation of an insoluble complex of iodide with copper during the HPLC run. Modified silica gel used in the composition of most reverse phase columns can adsorb metal ions including $\mathrm{Cu}(\mathrm{II})$ cation (17). This can lead to the buildup of the $\mathrm{Cu}(\mathrm{II})$ in the HPLC column over time following several injections of the trace element that can react with iodide anions to produce $\mathrm{CuI}$ (equation I) (18). At low $\mathrm{Cu}$ (II) concentrations (like the conditions in the trace element mixture), the concentration of produced $\mathrm{CuI}$ is below its $\mathrm{Ksp}(\mathrm{Ksp}$ of $\mathrm{CuI}=1.27 \times 10^{-12}$ ) (19) and, therefore, no precipitate is formed. Upon $\mathrm{Cu}$ (II) buildup in the column, the molar concentration of $\mathrm{Cu}$ (II) is raised leading to overpassing of the small $\mathrm{Ksp}$ of $\mathrm{CuI}$, formation of precipitates and blockade of the HPLC column. This explanation is very well in line with our observation that the column blockade was resolved upon washing of the column by a highly concentrated KI solution. Excess KI can react with $\mathrm{CuI}$ precipitate to produce anionic $\mathrm{CuI}_{2}^{-}$that is soluble in the mobile phase of HPLC (equation 2) (19).

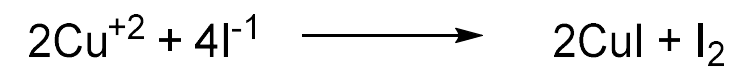

Equation (1)

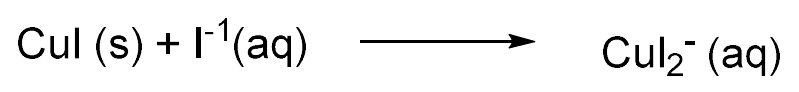

Equation (2)

Therefore, to solve the problem of the HPLC column blockade, after running each set of samples and standards, we washed the column with $2 \%$ solution of KI for around $2 \mathrm{~h}$ and made sure of the appropriate measurements after wash by running samples of known concentrations. Meanwhile, we used ICP-MS as an additional method for iodine measurement (on day 0,3 and 7) to validate our HPLC data. The results of both ICP-MS and HPLC showed iodine was within the permitted limits up to 7 days in all three storage conditions. However, the concentration of iodine was below the permitted level after 7 days of stability study in all storage conditions (Figure $5 \mathrm{~A}, 5 \mathrm{~B}, 5 \mathrm{C})$. Under acidic conditions, such as that of AHS compounded multi-trace element solution (Fig $1, \mathrm{pH} \sim 3.0$ ), selenious acid and iodide ion can react leading to the production of selenium and triiodide ion (21). Further investigation is required to clarify if this potential reaction has contributed to the reduced detected concentration of iodine in the AHS compounded multitrace element after 7 days of storage.

\section{CONCLUSION}

The AHS neonatal/pediatric multi-trace element formulation is physico-chemically stable up to 7 days in all three storage conditions in vials. The iodine level showed decline below acceptable limit after 7 days in all storage temperatures in vials. As for storage in syringes, our data is still inconclusive and need further evaluation in terms of $\mathrm{Zn}$ stability in solution.

Our results show that HPLC method of USP is not suitable for the measurement of iodine in the AHS compounded trace element mixture and perhaps any other trace element mixture containing $\mathrm{Cu}$ (II) cations and needed adjustments. Here, we used a concentrated solution of KI to wash the $\mathrm{C} 18$ column between runs, to make this analytical method acceptable and applicable to the study.

The stability of this product in terms of sterility, therapeutic activity and toxicological effects has not been evaluated. The sterility of this solution that is subjected to parenteral administration should be confirmed using USP sterility tests.

\section{ACKNOWLEDGEMENT}

This research was supported by AHS. We thank our colleagues from AHS who provided fund and expertise that greatly assisted the research. We would like to thank the University of Alberta Hospital pharmacy staff for compounding the trace element solutions. We also would like to show our gratitude to Dr. Chris Le's Lab and staff for assistance with ICP-MS for Iodine measurement, atomic absorption facility at the Chemical and Material Engineering (Dr. Shiraz Merali) and Earth 
and Atmospheric Sciences (Guangcheng Chen) for helping us with atomic absorption and ICP-MS analyses.

\section{REFERENCES}

1. Phillips GD, Odgers CL. Parenteral nutrition: current status and concepts. Drugs 1982 Apr;23(4):276-323.

2. Trace elements in human nutrition. Report of a WHO expert committee. World Health Organ Tech Rep Ser 1973;532:9-14.

3. Martindale R. Martindale: The Extra Pharmacopoeia. London: The pharmaceutical Press; 1982.

4. Tasman-Jones C, Kay R, Lee S. Zinc and copper defiency, with particular reference to parenteral nutrition. Surg Annu 1978;10:23-52.

5. Underwood E. Trace Elements in Human and Animal Nutrition. 4th ed.: New Academic Press; 1977.

6. Wolman SL, Anderson GH, Marliss EB, Jeejeebhoy KN. Zinc in total parenteral nutrition: requirements and metabolic effects. Gastroenterology 1979 Mar;76(3):458-467.

7. Ellenhorn MJ, Barceloux DG. Medical Toxicology Diagnosis and Treatment of Human Poisoning. : Elsevier; 1988.

8. Guidelines for essential trace element preparations for parenteral use. A statement by an expert panel. AMA Department of Foods and Nutrition. JAMA 1979 May 11;241(19):2051-2054.

9. Mirtallo J, Canada T, Johnson D, Kumpf V, Petersen C, Sacks G, et al. Safe practices for parenteral nutrition. JPEN J Parenter Enteral Nutr 2004 NovDec;28(6):S39-70.

10. United States Pharmacopeial Convention. USP monographs: Trace elements injection, United State Pharmacopeia. 39th ed.: United States Pharmacopeia; 2015. p. 3677-3678.
11. Vanek VW. Providing nutrition support in the electronic health record era: the good, the bad, and the ugly. Nutr Clin Pract 2012 Dec;27(6):718-737.

12. Vanek VW, Borum P, Buchman A, Fessler TA, Howard L, Shenkin A, et al. A Call to Action to Bring Safer Parenteral Micronutrient Products to the U.S. Market. Nutr Clin Pract 2015 Aug;30(4):559-569.

13. Vanek VW, Ayers P, Charney P, Kraft M, Mitchell R, Plogsted S, et al. Follow-Up Survey on Functionality of Nutrition Documentation and Ordering Nutrition Therapy in Currently Available Electronic Health Record Systems. Nutr Clin Pract 2016 Jun;31(3):401-415.

14. Corkins M, Balint J, Bobo E, Plogsted S, Yaworski J, Kuhn J. The ASPEN pediatric nutrition support core curriculum. 2nd ed.; 2015.

15. Burjonrappa SC, Miller M. Role of trace elements in parenteral nutrition support of the surgical neonate. $\mathrm{J}$ Pediatr Surg 2012 Apr;47(4):760-771.

16. Gargasz A. Neonatal and pediatric parenteral nutrition. AACN Adv Crit Care 2012 OctDec;23(4):451-64; quiz 465-6.

17. Chiron N, Guilet R, Deydier E. Adsorption of $\mathrm{Cu}(\mathrm{II})$ and $\mathrm{Pb}(\mathrm{II})$ onto a grafted silica: isotherms and kinetic models. Water Res 2003 Jul;37(13):3079-3086.

18. Johnson DA. Some Thermodynamic Aspects of Inorganic Chemistry. Some Thermodynamic Aspects of Inorganic Chemistry. second ed.; 1982. p. 98.

19. Myerson A. Handbook of Industrial Crystallization. Handbook of Industrial Crystallization. Second ed.; 2002. p. 5.

20. United States Pharmacopeial Convention. General Chapters:Injections and implanted drug products. United State Pharmacopeia. 41st ed.: United States Pharmacopeia; 2017. p. 5915-5916.

21. Neptune JA, King EL. The rate law for the reaction of selenious acid and iodide ion, Journal of American Chemical Society, 1953, 75(13) 3069-3072. 